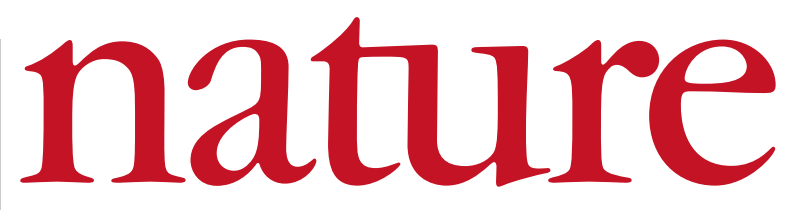

2 September 2004 Volume 431 Issue no 7004

\title{
Not just academic
}

The Russian Academy of Sciences is failing to provide either the quality of research or the scientific advice that reformers had been hoping for.

$\mathrm{T}$ hirteen years after the collapse of the Soviet Union, the Russian Academy of Sciences has so far been unable to reform itself into an organization that can provide the leadership that the nation's scientific community needs.

The academy's recent advice to Russian president Vladimir Putin that the Kyoto Protocol on climate change had "no scientific basis" (see page 12) is just one example of the academy's weakness. The advice didn't reflect the views of climate scientists inside or outside Russia. It is unlikely to have much effect on Putin's final decision on whether to ratify the Kyoto agreement, but it reflects badly on an academy whose centralized decision-making still has a Soviet flavour.

The Russian academy has two main functions, each vital to the country's development: it runs some 450 institutes, employing thousands of scientists, and is supposed to be the main body providing impartial scientific advice to the Russian government.

The academy traditionally comprised the élite of Russia's scientific intelligentsia. But in common with other public-sector enterprises in Russia, it has suffered a dramatic decline in wealth and reputation following the end of communism and the collapse of the Soviet military-industrial complex. Its institutes receive more than half of Russia's meagre public support for research and the great bulk of all money available for basic science. But critics say that it provides a poor return on this investment. Many of its institutes are isolated from Russia's real needs in industry or health, for example. They offer little in terms of technology innovation and are barely involved at all in science education.

A number of the academy's scientists still do good research in fields such as mathematics and some branches of physics, but the academy no longer produces a wide range of internationally competitive science. The most pressing priority for the heads of its institutes is to maintain their physical assets and political influence.

The academy is vital to the future of basic research in Russia. In a country where university-based researchers have little prospect of receiving stable research funds, the academy can still provide a home for the next generation of scientists. In order to do this effectively, it needs to reach out and strengthen its links with universities, industry, government agencies and hospitals. But there are far too many institutes and not enough resources to run them. Reform has been regarded as politically impossible in the past, but is now perilously overdue. An outside review of every institute's research performance, drawing on international expertise, could help determine which institutes are worth investing in.

It is clearly in Russia's interest to allow scientists to work in up-todate laboratories where academic freedom is respected. The country badly needs strong, self-assured and unbiased institutions, and a renewed and streamlined academy could become one of them. The atmosphere in Russia is not conducive to the development of such institutions, however. The July murder of journalist Paul Klebnikov, editor of the Russian edition of Forbes magazine, after it had published a list of the country's 100 wealthiest individuals, served to reinforce the perception that the political climate in Russia is growing ever more oppressive.

In this context, it is hard to see a way forward for Russian science. Academy researchers and managers must continue to strive as best they can for a better environment, in which their work will be properly supported and their advice garnered fairly, and taken seriously.

\section{Distributing the costs of climate change}

\section{Policy-makers must face up to the fact that global warming is creating winners and losers.}

A s with any profound disruption of society, such as war or hyperinflation, the changes brought about by our exploitation of fossil fuels will produce winners and losers. A session on climate extremes and their impacts, organized by Nature at the EuroScience Open Forum in Stockholm last week (see Nature 430, 277; 2004), discussed who will, and who should, pay for damage caused by global warming.

There are two basic strategies for dealing with global warming: climate-change mitigation, and adaptation to the changing conditions. For the next few decades, we will have no choice but to adapt. According to the 2001 report of the Intergovernmental Panel on Climate Change (IPCC), atmospheric carbon dioxide levels will rise until 2030 whether future emissions are curbed or not; the greenhouse gases that have already been emitted will dominate our medium-term future. But mitigation now can make a significant difference to the adaptation costs that will face our grandchildren.

So who benefits and who will have to pay? The question must be considered for each of the various effects of climate change. Take, for example, an increase in intense precipitation events, which is likely to occur in many areas over the next century, according to the IPCC assessment. Assuming that the main damage of intense rains lies in the flooding of land, those who live in a floodplain are most likely to lose money - in many European countries, flood damage is not insured. In most rich nations, people can choose between the pleasures of the riverside and the safety of a hill-top, so one might argue that floodplain dwellers have only themselves to blame. But a country such as the Netherlands does not offer many flood-proof building sites and, outside affluent societies, individual choices are limited.

There are winners too, including the builders who repair the damage and oil companies that benefit indirectly through the unrestricted sale of fossil fuels. But anyone who uses energy from fossil fuels at a price that does not account for climate-related costs of greenhousegas emissions is also 'winning' at someone else's expense. Winners and losers may be the same people, but usually they are not.

Inevitably, it is up to policy-makers to ensure that the costs of mitigation and adaptation are at least partly borne by those to whom climate change is attributable. Whatever the future of international treaties, lawyers and climatologists have interesting times ahead. 